\title{
TUTELA ADMINISTRATIVA DE BARRAGENS DE REJEITOS DE MINÉRIOS: A TUTELA ADMINISTRATIVA ESTATAL
}

\author{
ADMINISTRATIVE PROTECTION OF ORE TAILINGS DAMS: STATE \\ ADMINISTRATIVE PROTECTION
}

\author{
José Edmilson de Souza-Lima ${ }^{1}$ \\ Ellen Galliano de Barros ${ }^{2}$
}

\begin{abstract}
Resumo
O artigo objetiva analisar, pelo método bibliográfico, documental e legislativo, os moldes da tutela administrativa de segurança de barragens de rejeitos de minérios no Brasil. Justifica-se o tema pela fiscalização e controle públicos adequados de barramentos, diante das recentes tragédias causadas pelo rompimento dessas estruturas, com danos socioambientais catastróficos e irreparáveis. Examina-se, inicialmente, as peculiaridades da mineração e das barragens. Após, destaca-se a regulamentação nacional acerca da segurança de barragens de minérios, do seu planejamento até a operacionalização. Tem-se, finalmente, a constatação da frágil proteção das barragens de Mariana/MG e Brumadinho/MG, revelando o indispensável aperfeiçoamento do controle estatal, junto dos empreendedores.
\end{abstract}

Palavras-chave: Mineração; Barragens de Rejeitos de Minérios; Segurança de Barragens; Tutela Estatal.

\footnotetext{
${ }^{1}$ Licenciado e Bacharel em Ciências Sociais pela Universidade Federal do Paraná, Mestre em Sociologia Política pela Universidade Federal de Santa Catarina, Doutor em Meio Ambiente e Desenvolvimento pela Universidade Federal do Paraná. Entre 2014 e 2015 Coordenou o Núcleo de Pesquisa do Instituto Municipal de Administração Pública de Curitiba. Atualmente é pesquisador e docente do Programa de Pós-Graduação em Direito Empresarial e Cidadania do Centro Universitário Curitiba (UNICURITIBA) e do Programa de Pós-Graduação em Meio Ambiente e Desenvolvimento (PPGMADE) da Universidade Federal do Paraná (UFPR). Publicou dezenas de artigos em periódicos internacionais e nacionais e livros em diversas editoras. Suas pesquisas estão concentradas no entrelaçamento entre Ciências Ambientais, aportes sociológicos e jurídicos. Temas de interesse: sustentabilidade, decolonialidade, racionalidades, pluralismo epistêmico, interdisciplinaridade, ensino/pesquisa jurídica e meio ambiente. Pesquisador e Docente do Programa de Pós-Graduação em Direito Empresarial e Cidadania do Centro Universitário Curitiba. E-mail: zecaed@ hotmail.com

${ }^{2}$ Mestranda em Direito Empresarial e Cidadania pelo Centro Universitário Curitiba. Especialista em Direito Penal e Direito Processual Penal pelo Centro Universitário Curitiba (2019). Bacharel em Direito pela Pontifícia Universidade Católica do Paraná (2017). Assessora Jurídica da 4ª Câmara Criminal do Tribunal de Justiça do Estado do Paraná.
} 


\begin{abstract}
Resumen/Résumé
The article aims to analyze, through the bibliographic, documentary and legislative method, the models of the administrative guardianship of safety of ore tailings dams in Brazil. It is justified by adequate public supervision and control of buses, given the recent tragedies caused by the disruption of these structures, with catastrophic socioenvironmental damage. Initially, the peculiarities of mining and dams are examined. Then there is the homeland regulation on the safety of ore dams, from their planning to operationalization. Finally, we can see the fragile protection of the Mariana/MG and Brumadinho/MG dams, revealing the indispensable improvement of state control among entrepreneurs.
\end{abstract}

Keywords/Palabras-claves/Mots-clés: Mining; Ore Tailings Dams; Dam Safety; State Protection;

\title{
1 INTRODUÇÃO
}

Não há como negar a importância da mineração para o desenvolvimento econômico nacional, oportunizando a elevação de negócios comerciais, o número de empregos, além de garantir inúmeras atividades e produção de bens materiais. No entanto, a cadeia de lavra do minério deve atender os padrões técnicos e as diretrizes pátrias, a fim de não causar prejuízos ao meio ambiente e à vida humana. É o caso das barragens de rejeitos de minérios.

Por esse motivo, para a construção e funcionamento das estruturas de contenção, em suas várias modalidades, é imprescindível a proteção do direito fundamental ao meio ambiente ecologicamente equilibrado (art. 225, caput, da Constituição de 1988) e a realização da avaliação e estudo prévio de impactos ambientais ( $\$ 1^{\circ}$, do artigo supracitado), com a elaboração de relatórios definitivos. Ainda, para a concretização de tal estrutura, é necessária a permissão do Poder Público, através do licenciamento ambiental.

Fora isso, em relação às regulamentações infraconstitucionais, a segurança de barragens é indicada na Lei $\mathrm{n}^{\mathrm{o}} 12.334 / 2010$, que estabelece ordens gerais para todas as formas de contenção de líquidos e sólidos. Regulamentando a gestão de barragens de mineração, a Portaria $n^{0}$ 70.389/2017, da Agência Nacional de Mineração, especifica os modelos completos de fiscalização, controle e monitoramento a serem efetivados pela Administração Pública (órgãos públicos) e pelo empreendedor.

As regulamentações ainda prescrevem penalidades a serem aplicadas, acaso inadimplidas, haja vista a existência de danos potenciais e catastróficos causados ao equilíbrio 
ecológico e a toda a humanidade, como se observa nos casos do rompimento de barragens nos municípios de Mariana e de Brumadinho, ambas no Estado de Minas Gerais.

Os dois acontecimentos decorreram da segurança falha e negligente das barragens, causando prejuízos socioambientais e econômicos, apesar de toda a evolução na gestão das estruturas. E mais, direcionam o olhar para o aprimoramento da força-tarefa do Poder Público, com atuação efetiva dos empreendedores, vale dizer, com investimento financeiro na contratação de técnicos especializados para tal fim, na aplicação de medidas inovadoras de controle e fiscalização e nos cursos de qualificação, bem como na necessária fixação de sanções suficientes e que obstem a reiteração de ações displicentes.

\section{MINERAÇÃO E BARRAGENS DE REJEITOS: QUESTÕES ESPECÍFICAS}

Anteriormente à análise pormenorizada das barragens de rejeitos de minérios, cumpre ressaltar a questão da atividade econômica da mineração, a fim de melhor elucidar o objetivo principal do presente artigo.

Pois bem. A mineração possui relevante posição no desenvolvimento econômico nacional e internacional, através da intensificação da extração de minerais para fins comerciais, do crescimento do número de empregos e de negócios entre empresas diversas. Mais que isso, contribui para a realização de diversas atividades, tais como a informática, a construção civil, as telecomunicações e a indústria (FARIAS, 2015, p. 158-159), além de fazer parte da composição de bens materiais.

No caso do Brasil, por exemplo, a mineração corresponde a 4\% do Produto Interno Bruto, contribui com $25 \%$ do saldo comercial brasileiro, e mais, gera 180 mil empregos diretos, ultrapassando a linha de 2,2 milhões de empregos indiretos (GLOBO, 2018).

Assim, não há como olvidar a importância dessa atividade no cenário socioeconômico brasileiro. Todavia, como grande parte das produções empresariais, dentro da Sociedade de Risco, conduz ao surgimento de potenciais prejuízos ao meio ambiente e a toda humanidade, desde a lavra do bem mineral até a contenção dos seus rejeitos por meio de barramentos.

A mineração é executada pela manipulação dos recursos minerais, que figuram como bens da União, segundo artigo 20, inciso IX, da Constituição Federal, ente que possui competência privativa de legislar sobre eles, como define o artigo 22, inciso XII, da CRFB. Ao Estado cabe, então, a normatização e regulação dessa operação, mediante a fiscalização, incentivo e planejamento, conforme dispõe o artigo 174, da CRFB, influenciando na conduta 
do setor privado.

O aproveitamento dos recursos minerais está condicionado à concessão discricionariamente outorgada pelo Ministério de Estado de Minas e Energia, ou pela permissão concedida pelo Diretor-Geral do Departamento Nacional de Produção Mineral (DNPM), de acordo com o artigo $6^{\circ}$, da Lei n ${ }^{\circ}$ 9.314/96 (BRASIL, 1996). O DNPM é a autarquia responsável pela execução das políticas públicas no setor (FARIAS, 2015, p. 163).

A mineração é constituída pelas seguintes fases:

1. prospecção: é a fase que tem como objetivo a localização de concentrações anômalas de minerais economicamente interessantes; 2. exploração: é a fase de estudo, caracterização e avaliação das ocorrências encontradas na fase de prospecção; 3. desenvolvimento: é fase que engloba as operações de preparação da jazida para a lavra; 4. lavra ou explotação; 5. reabilitação ambiental: é a fase onde são feitos os trabalhos de reabilitação ambiental da área atingida pelo empreendimento mineral; e 6. beneficiamento: a mineração também pode incluir o tratamento preliminar do minério, através da britagem. (TAVEIRA, 1997, p. 14-15)

Após a fase do beneficiamento, chega-se à etapa do desaguamento, na qual se busca retirar a água do minério, para, então, conduzir o produto à baixa umidade. Por fim, tem-se a disposição dos rejeitos - materiais de baixo interesse comercial -, isto é, a deposição em lugar reservado e seguro, a fim de evitar a contaminação de solos e rios (MINAS JR., 2018). Neste momento, entra a função da barragem.

Muito se falou sobre o rompimento de barragens nos últimos anos, afinal, qual é a conceituação dessa estrutura? Trata-se de “[...] uma estrutura implantada em um curso de água, permanente ou temporário, para fins de contenção ou acumulação de água, de substâncias líquidas ou de misturas de líquidos e sólidos.” (ANA, 2019, p. 13).

Apenas a título de curiosidade, ressalta-se que existem barragens para diversos fins, tais como a geração de energia elétrica, para controle de inundações, irrigação de plantações, combate da seca, fornecimento de água para a indústria e consumo populacional, regularização de vazões, além da contenção de rejeitos (FRANCO, 2008, p. 22).

Interessa-nos tão somente a análise as estruturas de contenção de rejeitos minerais, que, como dito, se refere ao armazenamento de resíduos resultantes da fase do beneficiamento, sem valor econômico. Assim lecionam Romeu Thomé e Talita Martins Oliveira Lago:

As barragens de contenção de rejeitos da mineração são estruturas de controle ambiental construídas com o objetivo de conter os materiais resultantes do processo de beneficiamento do minério e/ou sedimentos oriundos das atividades, garantindo a qualidade da água e vazão dos corpos hídricos a jusante. $(2017$, p. 3) 
As primeiras estruturas construídas no Brasil são datados da mesma época do surgimento da mineração no Brasil, vale dizer, há cerca de 300 anos. A primeira barragem de rejeito foi construída em Mariana/MG, denominada Mina da Passagem. À época, foram utilizados métodos rudimentares para a lavagem e beneficiamento do rejeito mineral, sem acompanhamento de profissional da engenharia, além de serem projetadas de forma transversal no curso d'água (ANA, 2019, p. 18).

Todavia, apenas em 1930 as indústrias da mineração deram início ao investimento de barragens de tal modalidade, só que desta vez com técnicas mais seguras (ANA, 2019, p. 19). Durante as décadas de 1970 e 1980, a construção de barramentos de uso múltiplo foi ampliada no Brasil, incluindo os destinados à contenção de rejeitos, segundo explica Luiz Paniago Neves (2018, p. 8).

A barragem de rejeitos é estruturada pelo material derivado da mineração ou da indústria - barramento - possuindo um suporte inicial de contenção - dique de partida -, que tem a função de lançar os rejeitos para armazenamento, resultando um depósito com duas zonas denominadas praia e lagoa de decantação, conforme consta no Relatório de Segurança de Barragens da Agência Nacional de Águas (2018, p. 16).

Para além, consta a explicação do seu funcionamento:

\footnotetext{
A partir do momento em que a capacidade operacional é atingida, é necessário que o dique de partida seja elevado gradualmente, com o fim de acumular mais resíduos. Esse processo é denominado de alteamento, e pode ser executado, geralmente, de 3 formas diferentes, tendo como referência a direção em que a crista de alteamento se desenvolve em relação à posição inicial do dique de partida (ANA, 2019, p. 16)
}

Com relação às suas modalidades, dividem-se em três, respectivamente: alteamento a montante; alteamento a jusante; e alteamento de linha de centro.

O método a montante possui diques adicionais construídos pelo lançamento do aterro a montante do dique de partida, tendo a praia de rejeito como sua fundação. Os degraus da barragem são elevados na proporção do aumento de rejeitos, isto contra o barraco ou parede que lhe dá sustentação (GERAQUE, 2015). Possui a vantagem de ser mais econômico e de fácil execução, no entanto, exige maior cautela para manutenção, haja vista a possibilidade de erosão, inclusive de liquefação (ESPÓSITO, 2000, p. 8).

Em decorrência das tragédias anunciadas no rompimento das barragens a montante de Mariana (2015) e de Brumadinho (2019), ambas no Estado de Minas Gerais, a Agência Nacional de Mineração determinou a proibição da construção desse modelo em todo território 
nacional, além do mais, aquelas que estão desativadas devem ser eliminadas até 15 de agosto de 2021, e as que estão em funcionamento até 15 de agosto de 2023 (RESOLUÇÃO, 2019).

Diversamente, o método a jusante é constituído por degraus apoiados sobre eles mesmos, dando maior sustentação no bloco de rejeitos armazenados (GERAQUE, 2015). “Os diques adicionais são construídos com lançamento do aterro sobre o talude de jusante do alteamento anterior e sobre o terreno natural" (ANA, 2019, p. 16). Esse modelo é caracterizado por ser mais oneroso economicamente ao proprietário.

O método linha de centro, por sua vez, apresenta a construção dos diques pelo lançamento do aterro sobre a praia de montante e o talude de jusante (ANA, 2019, p. 16), melhor dizer, é a mistura dos outros dois métodos, sendo o mais seguro. A seguir, são apresentados os três formatos:

Figura 1 - Métodos Construtivos de barragens de rejeitos

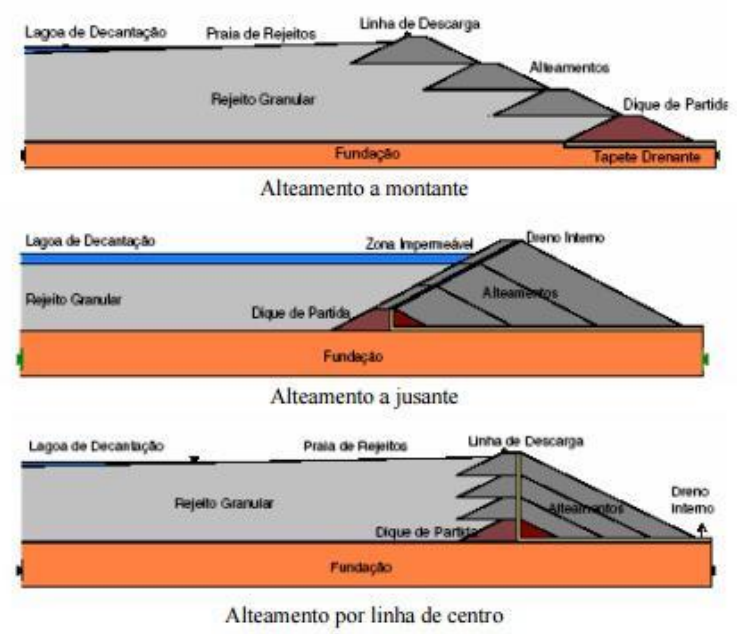

Fonte: ARAÚJO, 2006, p. 14-16

Por melhor que seja a contribuição do barramento de contenção de rejeitos, na cadeia da atividade mineraria, além da geração de empregos e desenvolvimento nacional, sabe-se que constitui fator de grave risco para a biodiversidade e a vida humana. Aliás, isso se agrava quando tem seu funcionamento na época da exploração intensa de recursos naturais, da superprodução industrial e da dependência de tais materiais para o bom andamento do mercado mundial.

Nessa toada, coloca em risco o meio ambiente ecologicamente sustentável, uma vez que pode afetar não apenas o solo (base da construção), como também espécies da fauna e da flora 
que, até então, habitavam no local. Outrossim, caso ocorra o rompimento, pode causar o óbito de animais terrestres e aquáticos, além de contaminar rios e outros cursos d'água.

No que tange aos seres humanos, pode afetar a população que vive nas proximidades da barragem, até mesmo funcionários que executem tarefas relacionadas à estrutura de contenção. Ainda, conforme destacam Thaís Antunes Mainarde e Juliane Altamann Berwig (2018, p. 177183), pode causar o óbito da população, o surto de doenças pela contaminação de minérios diversos, além de deixar marcas para os familiares dos entes falecidos e para sobreviventes, como danos morais e psicológicos, inclusive os decorrentes do desabrigamento.

Fora isso, existe a possibilidade de prejuízos para a execução de serviços públicos, tais como a interrupção da educação, do fornecimento de água, da distribuição de energia e perdas no transporte. Por derradeiro, tem-se a existência de danos econômicos na execução das atividades agropastoris, pesqueiras e comerciais (MAINARDE; BERWIG, 2018, p. 177-183).

Por essas razões, é imprescindível a tutela estatal e privada das barragens de rejeitos de minérios, por meio da fiscalização, do monitoramento da estrutura e da obediência às diretrizes constitucionais e infraconstitucionais, que especificam o formato da segurança adequada da estrutura. Assim, será possível evitar os riscos que foram explicitados.

\section{TUTELA ADMINISTRATIVA DE SEGURANÇA DE BARRAGENS DE REJEITOS DE MINÉRIOS}

\subsection{ASPECTOS GERAIS E PREVISÕES CONSTITUCIONAIS}

De início, menciona-se que a efetiva segurança de barragem de rejeitos minerais deve ser instituída já na projeção da estrutura, presente também na construção e no seu funcionamento, em virtude da obediência aos padrões técnicos e às diretrizes constitucionais e legais. Só assim será possível constatar rupturas iminentes e outras anomalias. A propósito:

Segurança de barragem é uma condição que visa a manter a sua integridade estrutural e operacional, para que cumpra sua finalidade, e a preservação da vida, da saúde, da propriedade e do meio ambiente. Uma barragem segura pode ser entendida como uma barragem cuidada, onde esforços, energia, atenção, recursos e profissionais capacitados são direcionados para uma boa concepção, um bom projeto, uma construção que segue as boas práticas da engenharia e, também, para as etapas posteriores à construção: primeiro enchimento, manutenção, operação e descomissionamento (desativação), se for o caso. (ANA, 2019, p. 25) 
Nesse sentido, a primeira determinação de proteção se vincula ao direito fundamental, de terceira geração, constante no capítulo da ordem social, no artigo 225, caput, da Constituição Federal, que visa a assegurar o equilíbrio ecossistêmico e a qualidade de vida intergeracional (CIRNE, 2018, p. 235). No $\S^{\circ}$ do mesmo artigo, tem-se algumas obrigações do Poder Público para a efetividade desse direito, dentre elas:

\footnotetext{
$\S 1^{\circ}$ Para assegurar a efetividade desse direito, incumbe ao Poder Público:

I - preservar e restaurar os processos ecológicos essenciais e prover o manejo ecológico das espécies e ecossistemas;

(...)

IV - exigir, na forma da lei, para instalação de obra ou atividade potencialmente causadora de significativa degradação do meio ambiente, estudo prévio de impacto ambiental, a que se dará publicidade;

V - controlar a produção, a comercialização e o emprego de técnicas, métodos e substâncias que comportem risco para a vida, a qualidade de vida e o meio ambiente; VII - proteger a fauna e a flora, vedadas, na forma da lei, as práticas que coloquem em risco sua função ecológica, provoquem a extinção de espécies ou submetam os animais a crueldade. (BRASIL, 1988)
}

E vai além. No $\S 2^{\circ}$, o constituinte tornou obrigatória a recuperação do meio ambiente degradado pela exploração de recursos minerais. No terceiro parágrafo, incluiu a responsabilização penal e administrativa para infratores ambientais - pessoas físicas e jurídicas -, sendo imprescindível a reparação dos danos (BRASIL, 1988).

Elevou, ainda, o meio ambiente com princípio da ordem econômica, alinhando a livre iniciativa ao ecossistema equilibrado, de acordo com o artigo 170, inciso VI (BRASIL, 1988). Portanto, conclui-se pela existência de diretrizes constitucionais do desenvolvimento econômico sustentável, com responsabilidade compartilhada entre corporações e o Poder Público.

A construção e o funcionamento das barragens de rejeitos, como etapa da mineração, devem, então, já num primeiro momento, estar em conformidade com a proteção do referido direito fundamental. Deve haver a minimização e a prevenção de barragens prejudiciais à coletividade, a punição de agentes que perpetrem infrações, a adoção de medidas de precaução - públicas e privadas - como o estudo prévio de impacto ambiental, o licenciamento ambiental, a fiscalização, o monitoramento e a existência de documentação regular do proprietário.

\subsection{ESTUDO PRÉVIO DE IMPACTO AMBIENTAL, RELATÓRIO IMPACTO AMBIENTAL E LICENCIAMENTO AMBIENTAL}


A tutela estatal põe em evidência o Poder de Polícia Ambiental, isto não apenas pelo cumprimento das obrigações constitucionais, mas também pelo licenciamento ambiental exigido para a construção e operação das barragens. Melhor dizer, segundo o artigo 10, caput, da Lei $n^{\circ}$ 6.938/81 (Política Nacional do Meio Ambiente), é obrigatória a licença prévia ambiental para a construção, instalação e funcionamento de empreendimentos e atividades potencialmente poluidores ou capazes de gerar degradação ecológica (BRASIL, 1981).

Entretanto, como pressuposto do licenciamento, faz-se necessário o prévio Estudo de Impacto Ambiental (EIA), acompanhado do Relatório de Impacto Ambiental (RIMA), ambos sendo espécies do gênero Avaliação de Impacto Ambiental (AIA), segundo dispõe o artigo $2^{\circ}$, da Resolução no 01/1986, do CONAMA, que abarca, de forma exemplificativa, o rol de atividades que dependem desses instrumentos (RESOLUÇÃO, 1986). Como se observa, a regulamentação está em consonância com o artigo $225, \S 1^{\circ}$, inciso IV, da CRFB, sujeitando as barragens de rejeitos minerais aos estudos prévios e seus relatórios.

De forma sucinta, a AIA é conceituada como um conjunto de procedimentos capazes de garantir a análise sistemática dos impactos ambientais de um projeto proposto e de suas alternativas (MILARÉ, 2018, p. 986). O Conselho Nacional do Meio Ambiente - CONAMA é o órgão competente para fixar as diretrizes relativas ao estudo prévio, com vistas ao licenciamento.

O EIA, por sua vez, representa o trabalho em campo, um estudo de potenciais alterações nas características ambientais e socioeconômicas, resultantes da construção de um empreendimento ou na realização de uma atividade (JAIN, 1977, p. 3). Tem por fim a constatação de possíveis prejuízos socioambientais.

Já o RIMA, é a forma conclusiva do EIA, pois inclui todos os benefícios e desvantagens do projeto a ser executado, seu diagnóstico, sua descrição, qualidade ambiental da área de influência, objetivos e justificativas (MILARÉ, 2018, p. 1007). Posteriormente, são iniciadas auditorias públicas periódicas, para fins de averiguação da obediência das diretrizes de proteção ambiental (MACHADO, 2008, p. 305).

Depois da avaliação dos impactos, será possível iniciar o licenciamento, que representa, em resumo, a manifestação do Poder de Polícia Administrativa, cujo objetivo recai sobre a prevenção de prejuízos ao meio ambiente, sendo um instrumento de política pública para resguardo do direito fundamental de terceira dimensão (CARNEIRO, 2014, p. 81).

O licenciamento ambiental é o método pelo qual o órgão ambiental competente autoriza a localização, a instalação e a execução de atividades com utilização de recursos naturais, de 
natureza nociva, dada a possibilidade de poluição e degradação, fazendo valer disposições legais e normas técnicas, como define o artigo $1^{\circ}$, inciso I, da Resolução CONAMA $\mathrm{n}^{\circ}$ $237 / 1997$.

Este controle ambiental feito pela Administração Pública se consolida através de uma série de exigências e procedimentos impostos para a estruturação de empreendimentos e operações. Divide-se, portanto, em três etapas, conforme consta do artigo $8^{\circ}$, da Resolução (1997):

\footnotetext{
Art. $8^{\circ}$ - O Poder Público, no exercício de sua competência de controle, expedirá as seguintes licenças:

I - Licença Prévia (LP) - concedida na fase preliminar do planejamento do empreendimento ou atividade aprovando sua localização e concepção, atestando a viabilidade ambiental e estabelecendo os requisitos básicos e condicionantes a serem atendidos nas próximas fases de sua implementação;

II - Licença de Instalação (LI) - autoriza a instalação do empreendimento ou atividade de acordo com as especificações constantes dos planos, programas e projetos aprovados, incluindo as medidas de controle ambiental e demais condicionantes, da qual constituem motivo determinante;

III - Licença de Operação (LO) - autoriza a operação da atividade ou empreendimento, após a verificação do efetivo cumprimento do que consta das licenças anteriores, com as medidas de controle ambiental e condicionantes determinados para a operação. (RESOLUÇÃO, 1997)
}

Em outras palavras, a licença prévia regulamenta a concessão das outras licenças, determinando os requisitos que devem conter. Obedecendo as condições, o licenciado tem o direito subjetivo às demais licenças (OLIVEIRA, 2005, p. 360). A segunda fase é a autorização do Estado para efetuar a atividade ou o empreendimento, levando em consideração medidas de controle ambiental, mitigadoras e compensatórias (MILARÉ, 2018, p. 1097). A última etapa, de outro lado, é caracterizada como instrumento de orientação e fiscalização para a operação do empreendimento, reduzindo potenciais riscos em desfavor do meio ambiente e garantindo os cuidados necessários (CARNEIRO, 2014, p. 100).

O licenciamento das barragens é feito junto das atividades de mineração e beneficiamento do minério extraído, possuindo ambas o condão de vilipendiar a natureza. Feita a abordagem inicial do controle do Estado, passa-se a examinar a Política Nacional de Segurança de Barragens.

\subsection{LEI No 12.334/2010, POLÍTICA NACIONAL DE SEGURANÇA DE BARRAGENS}

Até o século XX, havia o depósito irregular de rejeitos de minérios, considerados irrisórios e descartados nos cursos d'água, em terrenos próximos a eles, refletindo na obstrução 
de poços de irrigação e contaminação da área (BIZAWU; MOREIRA, 2017, p. 293). Não havia, dessa forma, a regulamentação adequada para a disposição de tais bens.

Foi apenas no ano de 2010, depois de intenso estudo sobre o necessário estabelecimento de regras para a segurança de barragens no país, que foi publicada a Lei $n^{\circ} 12.334$, que trata da gestão adequada das estruturas de contenção. A Legislação, instituindo a regulação estatal, decorreu dos problemas organizacionais e estruturais de inúmeras barragens - envelhecimento e falta de manutenção -, da incapacidade da gestão privada, além da desarticulação, até então, das esferas do Poder Público, fatores que propiciariam prejuízos socioambientais (NEVES, 2018, p. 10).

Nessa esteira, salienta-se que os objetivos propostos pela Lei, no seu artigo $3^{\circ}$, são os seguintes: garantir a observância dos padrões de segurança; regulamentar as ações de cautela, em todas as fases de planejamento, construção e operação do empreendimento; promover, de forma ampla, o monitoramento e a fiscalização da barragem; unir informações de segurança entre os governos; estabelecer normas técnicas para a avaliação da estrutura pelo Estado; e fomentar a cultura da segurança de barragens e administração de riscos (BRASIL, 2010).

Como fundamentos da Política Nacional de Segurança de Barragens (PNSB), tem-se, no artigo quarto, a garantia da participação e informação popular e social das ações preventivas e emergenciais; a segurança da barragem em todas as fases do empreendimento, repercutindo na sustentabilidade e na averiguação de potenciais efeitos socioambientais; e, sobretudo, a responsabilidade legal do empreendedor na efetivação da seguridade, com ações para garantila (BRASIL, 2010).

Assim, o ente particular tem a responsabilidade da administração do seu empreendimento, enquanto a Administração Pública faz a fiscalização do cumprimento das regulamentações do Plano de Segurança da Barragem (PSB). Dentre os órgãos de fiscalização, a Agência Nacional de Águas recebeu grande parte das atribuições, tais como a fiscalização de barragens de usos múltiplos, em corpos d'água da União, a de possibilitar a articulação entre os demais órgãos fiscalizadores, com o fim de aperfeiçoar a Política Nacional; estruturar, fixar e gerir o Sistema Nacional de Segurança de Barragens (SNISB); e coordenar, anualmente, a elaboração do Relatório de Segurança de Barragens (RSB), o qual será encaminhado ao Conselho Nacional de Recursos Hídricos (CNRH), cujo papel recai sobre o encaminhamento do documento ao Congresso Nacional (NEVES, 2018, p. 7).

Antes de tratar da regulamentação direcionada às barragens da mineração, salienta-se que a Lei abarca a definição de barragem, bem como de temas que lhe são associados, como 
sua segurança, órgãos públicos fiscalizadores, a gestão de risco, os danos potenciais decorrentes do seu rompimento, vazamento, infiltração ou do mau funcionamento, além da conceituação de empreendedor e de reservatório (BRASIL, 2010).

Também especificou, no parágrafo único, do artigo $1^{\circ}$, quais barragens devem ser submetidas ao PNSB, desde que possuam algumas características, quais sejam:

\footnotetext{
Art. 1ํ Esta Lei estabelece a Política Nacional de Segurança de Barragens (PNSB) e cria o Sistema Nacional de Informações sobre Segurança de Barragens (SNISB).

Parágrafo único. Esta Lei aplica-se a barragens destinadas à acumulação de água para quaisquer usos, à disposição final ou temporária de rejeitos e à acumulação de resíduos industriais que apresentem pelo menos uma das seguintes características:

I - altura do maciço, contada do ponto mais baixo da fundação à crista, maior ou igual a $15 \mathrm{~m}$ (quinze metros);

II - capacidade total do reservatório maior ou igual a $3.000 .000 \mathrm{~m}^{3}$ (três milhões de metros cúbicos);

III - reservatório que contenha resíduos perigosos conforme normas técnicas aplicáveis;

IV - categoria de dano potencial associado, médio ou alto, em termos econômicos, sociais, ambientais ou de perda de vidas humanas, conforme definido no art. 6… (BRASIL, 2010)
}

Englobou os instrumentos de aplicação da PNSB, no artigo $6^{\circ}$, como o sistema de classificação de barragens (dano potencial associado e categoria de risco); o Plano de Segurança de Barragem; o Sistema Nacional de Informações sobre a Segurança de Barragem; o Sistema Nacional de Informações sobre o Meio Ambiente; o Cadastro Técnico Federal de Atividades e Instrumentos e Defesa Ambiental; o Cadastro Técnico de Atividades Potencialmente Poluidoras ou Utilizadoras de Recursos Ambientais; e o Relatório de Segurança de Barragens (BRASIL, 2010).

Destaca-se, por derradeiro, outras previsões, senão as mais relevantes, em virtude da análise da tutela administrativa objetivada neste artigo, constantes nos artigos 16, 17 e 18, da Legislação. O artigo 16 dispõe sobre a atribuição do órgão fiscalizador de manter o cadastramento das barragens sob a sua jurisdição, sempre identificando os empreendedores (proprietários), a fim de compor o Sistema Nacional de Informações de Segurança de Barragens, bem como exigir do proprietário o cadastramento, suas atualizações, a anotação da responsabilidade técnica, por profissional habilitado pelo Sistema (engenharia, arquitetura, entre outros), relacionadas desde o estudo do empreendimento até a sua fiscalização. Mais ainda, exige do licenciado o atendimento das recomendações constantes nos documentos de inspeções e revisões de segurança (BRASIL, 2010). 
Em caso da existência de risco à segurança da barragem ou de acidentes associados, o organismo público deverá comunicar, imediatamente, a Agência Nacional de Águas e ao Sistema Nacional de Defesa Civil, conforme prevê o parágrafo primeiro do artigo 16 (BRASIL, 2010).

Paralelamente, o Poder Público impôs uma série de obrigações ao empreendedor, constantes no artigo 17, tais como a realização de projetos para o barramento; a garantia de recursos necessários e de serviço especializado para a segurança da estrutura; fornecer o acesso ao local do órgão fiscalizador e comunicá-lo sobre as suas alterações de comprometimento; manter e providenciar a documentação e providências exigidas para o seu planejamento, execução, manutenção e desativação (Plano de Segurança de Barragem; Plano de Ações Emergenciais; Revisões e Inspeções periódicas; e Cadastro); e atualizar seus dados no sistema nacional (BRASIL, 2010).

Também deve manter níveis dos reservatórios, em conformidade com o volume armazenado, características químicas e físicas do fluido, inclusive com o registro dos níveis de poluição do solo e do lençol freático, ambos influenciados pelo reservatório (BRASIL, 2010).

Finalmente, o artigo 18, caput, compreende a recuperação e a desativação, como providências a serem tomadas pelo empreendedor, no caso de descumprimento das condições de segurança da barragem, informando sempre o ente fiscalizador. Aliás, tais medidas devem possuir projeto específico. Na inércia do proprietário, o fiscalizador poderá executar providências de redução de riscos e seus danos relativos ao barramento, com o ressarcimento dos custos feito pelo seu responsável (BRASIL, 2010).

Complementarmente, o Conselho Nacional de Recursos Hídricos instituiu as Resoluções $n^{\circ} 143$ e 144, as duas datadas de 2012, regulamentando os artigos $7^{\circ}$ e 20, da Lei ${ }^{\circ}$ 12.334/2010. A Resolução $n^{\circ}$ 143/2012 apresenta critérios gerais de classificação de barragens, pela categoria de risco, dano potencial associado e seu volume. Para tanto, leva-se em conta características técnicas do barramento, o seu estado de conservação e plano de segurança, bem como dano crítico potencial, proveniente de falhas da estrutura (por exemplo, rompimentos e vazamentos) (NEVES, 2018, p. 26-29). A classificação é elaborada pelos fiscalizadores, a cada cinco anos, a partir da atividade dos seus agentes no local ou por recebimento de informações. Na omissão de dados, o critério será fixado no grau máximo.

Em acréscimo, a Resolução no 144/2012 trouxe a definição de acidente e incidente de barragens, como também apresentou diretrizes gerais para a implementação de instrumentos da 
Política Nacional de Segurança de Barragens, de cunho informativo, técnico, integrativo e gerenciamento (NEVES, 2018, p. 29-32).

\subsection{PORTARIA No 70.389/2017, DA AGÊNCIA NACIONAL DE MINERAÇÃO}

Após a verificação das diretrizes legais, empregadas como norte para as regulamentações específicas de segurança de barragens em geral, inicia-se o exame da forma intervenção do Poder Público na gestão de barramentos de rejeitos de minérios.

Em primeiro lugar, a Agência Nacional de Mineração (ANM), autarquia federal ligada ao Ministério de Minas e Energia (MME), é o ente responsável pela fiscalização das referidas barragens.

Nesta senda, publicou a Portaria $\mathrm{n}^{\mathbf{0}} 70.389 / 2017$, que criou o Cadastro Nacional de Barragens de Mineração, além de estabelecer o Plano de Segurança, Inspeções Regulares e Especiais de Segurança de Barragens de Mineração e o Plano de Ações de Emergência para Barragens de Mineração (NEVES, 2018, p. 46).

Seguindo a normativa do artigo $1^{\circ}$, da Lei $n^{\circ} 12.334 / 2010$, reitera as exigências para que a barragem seja submetida ao Plano de Segurança de Barragem. Em seguida, define, detalhadamente, a barragem de contenção de rejeitos:

\footnotetext{
Art. $2^{\circ}$ Para efeito desta Portaria consideram-se:

(...)

II. Barragens de Mineração: barragens, barramentos, diques, cavas com barramentos construídos, associados às atividades desenvolvidas com base em direito minerário, construídos em cota superior à da topografia original do terreno, utilizados em caráter temporário ou definitivo para fins de contenção, acumulação, decantação ou descarga de rejeitos de mineração ou de sedimentos provenientes de atividades de mineração com ou sem captação de água associada, compreendendo a estrutura do barramento e suas estruturas associadas, excluindo-se deste conceito as barragens de contenção de resíduos industriais; (PORTARIA, 2017)
}

O cadastramento de todas as barragens da atividade da mineração se apresenta como obrigação direcionada ao empreendedor, a ser incluído no Sistema Integrado de Gestão de Segurança de Barragens de Mineração (SIGSBM), compreendendo aquelas em construção, operação e desativadas, sempre de forma periódica e atualizada, segundo dispõe o artigo $3^{\circ}$, da Portaria (2017)

Quanto à classificação das estruturas, a Portaria segue o padrão instituído pela Política Nacional de Segurança de Barragens. Repisa-se. Seguem os critérios de Categoria de Risco (enfatiza a estrutura do empreendimento), Dano Potencial Associado (potencial perdas de vidas 
e de impactos socioeconômicos e ambientais) e Volume do reservatório (graduação do volume) (ANA, 2019, p. 27), nivelados em alto, médio e baixo, com classes A, B, C, D e E. Para isso, deve ser encetada pelo empreendedor, com acompanhamento de profissional técnico especializado, a construção de um mapa de inundação, levando em consideração características geográficas, o contexto atualizado da estrutura e a ocorrência de eventuais danos, consoante às regras dos artigos $5^{\circ}$ e $6^{\circ}$ (PORTARIA, 2017).

Para fins de regularização da gestão adequada dos barramentos, também consta a necessária implantação do sistema de monitoramento pelo seu responsável (artigo $7^{\circ}$ ), guardando dependência da classificação anteriormente elaborada. Aliás, aquelas que possuem classificação alta devem ser monitoradas em tempo integral, com uso de vídeo e armazenamento. De mais a mais, os dados resultantes dessa operação devem ser repassados à Defesa Civil e ao Departamento Nacional de Produção Mineral.

No que tange ao Plano de Segurança de Barragem, a regulamentação evidencia a obrigatoriedade da sua realização pelo empreendedor, afinal pretende contribuir para a adequada administração do barramento. Essa coletânea de documentos deve estar disponível próximo da estrutura da barragem ou no escritório da equipe de segurança, sendo constituída por quatro volumes (físicos ou eletrônicos), respectivamente (artigo $9^{\circ}$ ): "I. Volume IInformações Gerais; II. Volume II - Planos e Procedimentos; III. Volume III - Registros e Controles; e IV. Volume IV - Revisão Periódica de Segurança de Barragem.” (NEVES, 2018, p. 50)

Acrescente-se, ainda, o quinto volume (físico) referente ao Plano de Ação Emergencial de Barragens de Mineração, para aquelas de dano potencial alto e/ou com população a jusante ou impacto ambiental com 10 pontos. Todos os volumes devem guardar proporção com a complexidade da estrutura, suficientes às condições de segurança, elaborado por profissionais especializados contratados para tal fim e regularmente atualizados. Por fim, deve ser elaborado até o início do primeiro enchimento da barragem (PORTARIA, 2017).

Em relação à Revisão Periódica de Segurança da Barragem efetivada por equipe multidisciplinar, prevista nos artigos 13 a 15, da Portaria, pretende atestar o estado geral da segurança do barramento, considerando a sua estrutura (estabilidade, desempenho, segurança hidráulica, realização de procedimento e documentação), com a recomendação de providências para o seu adequado funcionamento (ANA, 2019, p. 26). Ao final, deve ser elaborada a Declaração de Condição de Estabilidade, assinada por profissional externo da empresa proprietária, a ser entregue à ANM (NEVES, 2018, p. 52). 
No caso de instabilidade constatada ou na falta da Revisão, se existir o processo de reaproveitamento de rejeitos, haverá a interdição imediata da estrutura. A periodicidade da atividade é estabelecida nos seguintes prazos: 03 (três) anos para DPA alto; 05 (cinco) anos para DPA médio; e 07 (sete) anos para DPA baixo (PORTARIA, 2017).

As Inspeções Regulares de Segurança de Barragem (IRSB), instituídas pelos artigos 16 a 22, por sua vez, compreendem o preenchimento de alguns documentos, como as (1) Fichas de Inspeção Regular, contendo dados de componentes e estruturas ligadas à barragem, além dos itens do Estado de Conservação associada à Categoria de Risco; e (2) Relatório de Inspeção Regular da Barragem, conhecido com RIRB, contendo a Declaração de Condição de Estabilidade, com responsabilidade do profissional que o elaborou, e mais, com a identificação do representante legal do empreendedor e da equipe externa contratada para a operação, descrição das inspeções quinzenais no semestre e seus diagnósticos, caracterização tecnológica dos rejeitos, níveis de controle e ciência do empreendedor.

A IRSB deve conter ainda a Declaração de Condição de Estabilidade, que, segundo Neves (2018, p. 54), é um documento formal entregue ao órgão fiscalizador (ANM), cujo conteúdo recai sobre a estabilidade da barragem auferida por profissional técnico contratado pelo proprietário. O Extrato de Inspeção Regular, preenchido quinzenalmente, possui informações sobre as fichas de inspeção, e viabiliza a gestão remota pelo ente fiscalizador.

A ANM fez questão de regulamentar, também, nos artigos 23 a 28, as Inspeções Especiais de Segurança de Barragem (IESB), concretizadas com detalhamento e maior frequência, em razão do necessário controle ou extinção de anomalia com pontuação máxima de 10 (dez) pontos. Desta feita, o instrumento de segurança é realizado diariamente, com registro nas Fichas de Inspeção Especial até o controle ou o desaparecimento da anomalia. Para comunicar o ente fiscalizador, faz-se necessário o preenchimento do Extrato de Inspeção de Segurança Especial de Barragem e, finalmente, produzir o Relatório Conclusivo de Inspeção Especial, de modo completo (com avaliações, registros fotográficos e comparações técnicas) e com anotação da responsabilidade técnica (NEVES, 2018, p. 56- 59).

Adentrando aspectos sobre as ações e situações emergenciais, a Portaria em comento traz, nos artigos 29 a 35, o Plano de Ação de Emergência para Barragens de Mineração (PAEBM), definido como documento técnico elaborado pelo empreendedor, no qual estão indicadas as situações de emergência da barragem, as providências a serem adotadas e agentes a serem acionados. A cópia do Plano é entregue às autoridades públicas. 
Compõe-se de treinamentos, notificações, descrição da barragem e suas estruturas, formas de detecção, avaliação e classificação das situações de emergência, medidas preventivas e corretivas, recursos materiais e logísticos pelo empreendedor, instalação de sistema de monitoramento e de alerta da população (por exemplo, Zona de autossalvamento), relatórios de causas e consequências de impactos, autoridades competentes a serem notificadas e mapas de zonas a serem afetadas pelo dano da barragem (Mapa de inundação). Ao seu proprietário cabe uma série de encargos de natureza preventiva vinculados ao PAEBM. Tudo isso para mitigar prejuízos ecossistêmicos e sociais (NEVES, 2018, p. 59-60).

Relativo às Situações de Emergência, a regulamentação da ANM destaca as duas hipóteses de instauração (artigo 36), isto é, na Inspeção Especial de Segurança de Barragem ou em qualquer outra situação com potencial comprometimento da estrutura. Em seguida, o coordenador do PAEBM classificará a emergência, com disponibilidade para a Defesa Civil.

A classificação é estabelecida em três níveis (artigo 37): Nível 1, no início da Inspeção de Segurança Regular ou em situação diversa de comprometimento do barramento; Nível 2, quando o resultado do Plano de Ação não for controlado; e Nível 3, quando a ruptura está próxima de ocorrer ou está em execução (PORTARIA, 2017).

Ressalta-se que os profissionais legalmente habilitados, com registro no Conselho Regional de Engenharia e Agronomia - CREA, são encarregados da realização do estudo e mapa de inundação, do Relatório de Inspeção de Segurança Regular, Relatório Conclusivo de Inspeção Especial, Revisão Periódica de Segurança de Barragem (nesse caso, com o serviço de equipe multidisciplinar), da Declaração de Condição de Estabilidade, do Plano de Ações de Emergência para Barragens de Mineração, bem como do documento para descadastramento por fechamento ou descaracterização de barragem (PORTARIA, 2017).

Já em relação à elaboração do Plano de Segurança de Barragens, o preenchimento das Fichas de Inspeção Regular e Especial e dos Extratos de Inspeção Regular e Especial é de responsabilidade de equipes ligadas à segurança da barragem (interna ou externa ao proprietário do empreendimento) (PORTARIA, 2017).

Por fim, a Portaria trata das sanções administrativas, aplicadas no caso de descumprimento das obrigações nela previstas e por informação inverídica ao Departamento Nacional de Produção Mineração (DNPM), sem afetar outras sanções previstas em lei (criminal, cível e administrativa). Nesse sentido, o artigo 46 indica, de forma clara, que o infrator sofrerá as reprimendas previstas no artigo 100, II, combinado com o artigo 54, do Decreto $\mathrm{n}^{\circ}$ 


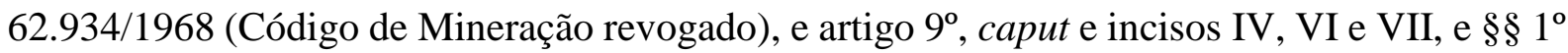
e $2^{\circ}$, da Lei $n^{\circ} 7.805 / 89$ (PORTARIA, 2017).

Observa-se que os referidos artigos do Código de Mineração faziam menção à condenação de multa de 10 salários mínimos mensais, de maior valor no país, em virtude da violação das obrigações relativas ao titular da concessão da lavra de minérios (BRASIL, 1968). No entanto, o Código foi revogado pelo Decreto n ${ }^{\circ}$ 9.406/2018.

Pelo atual Decreto, segundo o artigo 70, aquele que não atender o disposto na Política Nacional de Segurança de Barragens, obrigação prevista no artigo 34, inciso XIX, será condenado à multa de $\mathrm{R} \$ 1.619,63$ a $\mathrm{R} \$ 3.239,26$, conforme estabelecido em Resolução da ANM (BRASIL, 2018).

Consoante os incisos e parágrafos mencionados do artigo $9^{\circ}$, da Lei $\mathrm{n}^{\circ} 7.805 / 89$, aquele que não cumprir com os encargos de executar os trabalhos de mineração em conformidade com normas técnicas e regulamentares do DNPM e de órgão ambiental competente, deixando de adequar a lavra com o resguardo ambiental ou de providenciar medidas exigidas pela Administração Pública, será advertido e receberá multa, ambas previstas nos incisos I e II do art. 63, do Decreto-Lei no 227/1967, além de ter cancelado o licenciamento da lavra (BRASIL, 1989).

Destaca-se que a multa inicial pode variar de 10 a 200 vezes o Maior Valor de Referência - MVR, de acordo com a disposição do art. $2^{\circ}$ da Lei $n^{\circ}$ 6.205/1975. As hipóteses e os respectivos valores são definidos em portaria do Diretor-Geral do DNPM (BRASIL, 1989).

\section{TRAGÉDIAS ANUNCIADAS PELO ROMPIMENTO DE BARRAGENS E APRIMORAMENTO DA FISCALIZAÇÃO PÚBLICA}

A par de todas essas características, tanto da natureza e funcionamento da barragem de rejeitos de minérios, quanto das regulamentações específicas da sua segurança, urge examinar, na prática, dois casos emblemáticos de inadequação da gestão de barragens. Trata-se, portanto, do rompimento das barragens em Mariana/MG e Brumadinho/MG.

O primeiro caso ocorreu em 05 de novembro de 2015, no Distrito de Bento Rodrigues, na cidade de Mariana, em Minas Gerais, onde se rompeu a barragem de Fundão e, na sequência, a de Santarém. Como resultado, foi despejado um volume estimado em 62 milhões de $\mathrm{m}^{3} \mathrm{de}$ rejeitos de minérios. A empresa Samarco S/A era responsável pela extração e beneficiamento do minério, cuja propriedade é dividida entre as empresas Vale S/A e BHP Biliton Brasil Ltda. 
O mar de lama contendo rejeitos avançou sobre planícies de inundações de rios tributários, vegetações, alcançando o Rio Doce. Atingiu o Município de Mariana, causou 19 óbitos de pessoas e aproximadamente 207 imóveis foram destruídos.

Conforme o laudo pericial, constituinte do inquérito criminal, o rompimento ocorreu pela conjunção dos seguintes motivos: processo de liquefação; elevada saturação dos rejeitos arenosos; falha do monitoramento da estrutura e o defeito de alguns de instrumentos da barragem; alta taxa anual do volume de lama estocado; assoreamento do "dique 2", que permitiu a infiltração da área dos rejeitos arenosos; deficiência do sistema interno de drenagem; licenciamento ambiental que não apresentou informações essenciais e já indicava potenciais danos (MAINARDE; BERWIG, 2018, p. 174-177).

Passados pouco mais de quatro anos da tragédia, a Samarco S/A tão somente pagou $23 \%$ (R 72 milhões) do valor das multas ( $\mathrm{R}$ \$ 301,6 milhões) por danos ambientais impostas pela Secretaria de Meio Ambiente e Desenvolvimento Sustentável de Minas Gerais (SEMAD, 2019). As demais multas estão com recurso em andamento ou análise do Poder Judiciário, e uma foi suspensa liminarmente.

O Instituto Brasileiro do Meio Ambiente e dos Recursos Naturais Renováveis (IBAMA) aplicou multas de R \$ 350,7 milhões, que não tinham sido pagas até o início de 2019 (FONTES; GOMES, 2019). Em data de 25 de outubro de 2019, a Câmara de Atividades Minerárias do COPAM/MG autorizou a licença para a Samarco S/A voltar a operar no Complexo do Germano, onde ocorreu o acontecimento (SEMAD, 2019).

Se não bastasse o primeiro acontecimento, em 25 de janeiro de 2019 rompeu-se a barragem de Mina do Feijão, no Município de Brumadinho, no mesmo Estado, tendo como resultado o despejo de aproximadamente 14 milhões de toneladas de lama contendo rejeitos de minérios de ferro, os quais percorreram 08 quilômetros, inclusive poluindo o Rio Paraopeba. Causou, ainda, o óbito de 259 pessoas e o desaparecimento de outras 11.

De acordo com o Relatório Técnico da ANM (2019, p. 111-115), o rompimento foi causado por uma série de falhas na gestão da segurança de barragens, a propósito: informações da Barragem I não anexadas ao Plano de Segurança da Barragem ou não disponibilizadas para a fiscalização; situações anômalas na Barragem I que não foram comunicadas à ANM; subjetividade e falta de dados exatos na elaboração do RPSB e do RISR; ausência de exigência de ensaios e análises para avaliar condição de estabilidade da estrutura, aceitando margens de erro; processo de piping (abertura de canais dentro da estrutura de contenção, dificultando a drenagem do material); falta de drenos internos; carência de dados suficientes e de 
levantamentos dos parâmetros geotécnicos nas etapas de construção da Barragem I; descumprimento de obrigações do empreendedor, que envolviam a comunicação da ANM.

As obrigações violadas consistiram na inexistência de descrição do Sistema de Alerta e da sua operação, do plano de treinamentos internos e seus registros do Plano de Ações de Emergência para Barragens de Minérios e do protocolo de recebimento desse documento pelas autoridades competentes (Barragens I, IV, IV-A e VI). Ainda no tocante à Barragem I, as recomendações para a condição de estabilidade não foram executadas pelo empreendedor; não foi encontrado Projeto Executivo do $3^{\circ}$ alteamento; as Fichas de Inspeção Regular 11 e 12/2012 não refletem informações inseridas nos Extratos de Inspeção Regular inseridos no SIGBM. Os Extratos de Inspeção Regular 01 e 02/2012 não refletiam a realidade da estrutura, omitindo inclusive o estado de emergência de parte dela. A população potencialmente afetada na Zona de autossalvamento não foi alertada, em tempo e de forma eficaz, pelos sistemas de alerta e de avisos do PAEBM. Por fim, não foi iniciada inspeção especial de segurança, o mesmo ocorrendo com o carreamento de sólidos e pontuação máxima no item de percolação (ANM, 2019, p. 113-115).

Desde o ocorrido, o Ministério Público Federal em conjunto com outras entidades públicas instaurou força-tarefa para apurar as responsabilidades, colher provas e mitigar os prejuízos socioambientais. Nesse meio tempo, 56 barragens de rejeitos de minérios foram interditadas pela ANM, por falta de laudo ou condição de estabilidade, bloqueios de bilhões de reais foram decretados na conta da Vale S/A, que, aliás, foi condenada a pagar R 11 bilhões para garantir reparações (RODRIGUES, 2019). Também recebeu multa de $\mathrm{R} \$ 329.204,25$, aplicada pela SEMAD, em razão da emissão de laudos ambientais falsos, desconsiderando as recomendações de consultorias, além disso, teve o cancelamento das licenças para o reaproveitamento de minerais dispostos na barragem (HOJE EM DIA, 2019).

No mesmo ano, a ANM decidiu pela proibição da construção e operação de barragens a montante. Paralelamente a tais providências, foram adotadas outras medidas, como pedidos de reparação, apurações de responsabilidade criminal, negociações de acordos para adoção de medidas emergenciais e reparadoras, defesa de crianças e adolescente, fauna, patrimônio cultural, segurança hídrica, contratação de auditoria independente, suspensão parcial de atividades de certificação de sistema de gestão ambiental e, por fim, o combate a fraudes na rede (MPMG, 2019, p. 05-11).

Se por um lado vislumbra-se a evolução legislativa e administrativa para a segurança de barragens, exigindo-se cada vez mais do empreendedor a adequada administração do seu 
empreendimento, ainda que em passos lentos, por outro lado, o presente cenário atesta a predominância do lucro do particular em detrimento da proteção socioambiental, com aval do Estado.

Nessa lógica, a fiscalização do Poder Público ainda é precária, ineficaz e insuficiente, tanto por uma questão de falta de equipe técnica especializada para tal fim, quanto pela redução de horas de capacitação específica de funcionários para a segurança de barragens e pelo descenso de recursos financeiros para executar tarefas de controle, consoante os dados levantados por Neves (2018, p. 9) e pela ANA (2018, p. 43-49). Como consequência disso, a probabilidade da permanência de barragens em condição de instabilidade e próximas de causar danos socioambientais e econômicos catastróficos é consideravelmente alta.

Em virtude disso, cumpre ao Estado, junto dos proprietários de barramentos, investir em medidas eficazes e inovadoras de fiscalização, de colaboração mútua de repasse de dados sobre a condição da segurança, e claro, incentivar decisões e comportamentos em conformidade com a proteção ecossistêmica. Caso haja violações à gestão esperada, deve ser aplicada penalidade suficiente e que constitua óbice à reiteração da ação irregular. Para tanto, sugere-se a exigência da fixação de programas de compliance.

\section{CONCLUSÃO}

Diante do exposto, verifica-se que, apesar da importância da mineração no avanço socioeconômico do país, todas as fases da cadeia dessa atividade devem estar alinhadas à proteção da vida humana e do meio ambiente, conforme dispõe o artigo 225 , caput, da CFRB. Não é diferente com a etapa de contenção de rejeitos de minérios feita por barragens, a montante, a jusante e na linha de centro.

Nesse cenário, a Administração Pública exige a realização de Avaliação de Impacto Ambiental (AIA), que compreende o Estudo Prévio de Impacto Ambiental (EIA) e o Relatório de Impacto ao Meio Ambiente (RIMA), segundo dispõe o $§ 1^{\circ}$, do artigo 225, da CFRB, como condições para posterior licenciamento ambiental para a construção e funcionamento da estrutura de contenção, de acordo com artigo $1^{\circ}$, inciso I, da Resolução CONAMA n 237/1997.

Mais que isso, para a adequada implantação da barragem de minério, é imprescindível o atendimento às previsões gerais da Lei no 12.334/2010 (Política Nacional de Segurança de Barragens) e específicas da Portaria ANM no 70.389/2017 (Segurança de Barragens de Minérios), configurando o Poder de Política Ambiental executado pelo Estado, mediante a 
cobrança do empreendedor no estabelecimento de um Plano de Segurança de Barragens, Revisões e Inspeções de Segurança, o preenchimento de documentos relativos à condição de estabilidade, fichas e extratos de fiscalização e controle, Plano de Ações de Emergências para Barragens de Mineração, Situações de Emergência, além da comunicação de dados aos órgãos competentes visando à classificação atualizada da estrutura. No caso de não atendimento, é prevista a aplicação de penalidades, respectivamente, multas e advertências.

Não obstante a evolução da regulamentação pátria referente à tutela administrativa de segurança de barragens de minérios, observa-se o seu necessário aprimoramento, dada a reiteração de tragédias socioambientais e econômicas decorrentes dos recentes casos de rupturas de barragens, em curto lapso temporal. Prejuízos que foram causados pela falha da gestão, fiscalização e controle, ora por informações falsas ou omitidas ao Poder Público, ora pela ausência da implantação de instrumentos de prevenção. Acrescente-se, ainda, o não investimento estatal em pessoal técnico especializado para a supervisão efetiva dos empreendimentos e em cursos de capacitação.

A par disso, cumpre ao Estado, acompanhado dos empreendedores, atuar, de forma colaborativa, para a seguridade dos barramentos, durante o seu planejamento, construção e operação, sem negligenciar as condições da engenharia da estrutura e de potenciais danos. Uma barragem segura é aquela atende às diretrizes constitucionais e legais, aos padrões técnicos, tornando regular o funcionamento de medidas de prevenção e de controle (monitoramento, revisões periódicas e constatação de situações de emergência) e, sobretudo, obsta a possibilidade de novos prejuízos a toda a comunidade.

\section{REFERÊNCIAS}

ANA. Relatório de Segurança de Barragens 2018. Agência Nacional de Águas, Brasília, 2019. Disponível em: http://www.snisb.gov.br/portal/snisb/relatorio-anual-de-seguranca-debarragem/2018/rsb2018_0312.pdf. Acesso em: 01 jan. 2019.

ANM. Relatório Técnico sobre barragem de Brumadinho. Agência Nacional de Mineração, Brasília, 23 set. 2019. Disponível em: http://www.anm.gov.br/parecer-007-2019-brumadinhofinal. Acesso em: 12 jan. 2020.

ARAÚJO, Cecília Bhering de. Contribuição ao Estudo do Comportamento de Barragens de Rejeito de Mineração de Ferro. 2006 VII. 133 p. Dissertação (Mestrado em Engenharia Civil) - Universidade Federal do Rio de Janeiro, Rio de Janeiro, 2006. Disponível em: http://www.coc.ufrj.br/pt/component/docman/?task=doc_download\&gid=1655\&Itemid=. Acesso em: 01 jan. 2020. 
BIZAWU, Kiwonghi; MOREIRA, Renan Lucio. Licenciamento ambiental e Política Nacional de Segurança de Barragem Lei 12.334/2010. Revista Jurídica. Curitiba, v. 3, n. 48, 2017. p. 271-298.

BRASIL, Decreto no 62.934, de 02 de julho de 1968. Brasília: DOU de 21/08/1968.

Disponível em: http://www.planalto.gov.br/ccivil_03/decreto/1950-1969/D62934.htm. Acesso em: 06 jan. 2020.

BRASIL. Lei no 6.938, de 31 de agosto de 1981. Brasília: DOU de 02/09/1981. Disponível em: http://www.planalto.gov.br/ccivil_03/LEIS/L6938.htm. Acesso em: 06 jan. 2020.

BRASIL. Constituição Federal da República, de 05 de outubro de 1988. Brasília: DOU de 05/10/1988 Disponível em:

http://www.planalto.gov.br/ccivil_03/constituicao/constituicao.htm. Acesso em: 04 jan. 2020.

BRASIL. Lei no 7.805, de 18 de julho de 1989. Brasília: DOU de 11/10/1989. Disponível em: http://www.planalto.gov.br/ccivil_03/LEIS/L7805.htm. Acesso em: 06 jan. 2020.

BRASIL. Lei n 9.314, de 14 de novembro de 1996. Brasília: DOU de 18/11/1996. Disponível em: http://www.planalto.gov.br/ccivil_03/LEIS/L9314.htm\#art1. Acesso em: 12 jan. 2020.

BRASIL. Lei no 12.334, de 20 de setembro de 2010. Brasília: DOU de 21/09/2010. Disponível em: http://www.planalto.gov.br/ccivil_03/_Ato2007-2010/2010/Lei/L12334.htm. Acesso em: 02 jan. 2020.

BRASIL, Decreto n 9.406, de 12 de junho de 2018. Brasília: DOU de 13/06/2018. Disponível em: http://www.planalto.gov.br/ccivil_03/_Ato20152018/2018/Decreto/D9406.htm\#art83. Acesso em: 06 jan. 2020.

CARNEIRO, Cheila da Silva Passos. Licenciamento Ambiental: Prevenção e Controle. Rio de Janeiro: Lumen Juris, 2014.

CIRNE, Mariana Barbosa. O que é direito constitucional ao meio ambiente ecologicamente equilibrado? Revista de Direito Ambiental. São Paulo, v. 90, a. 23, abr./jun., 2018. p. 223241.

ESPÓSITO, Tereza de Jesus. Metodologia Probabilística e Observacional aplicada a Barragens de Rejeito construídas por Aterro Hidráulico. 2000. 363 p. Tese (Doutorado em Geotecnia) - Universidade de Brasília, Brasília, 2000. Disponível em: https://www.geotecnia.unb.br/index.php/pt/downloads/teses/004-2000.pdf. Acesso em: 07 jan. 2020.

FARIAS, Talden. A atividade minerária e a obrigação de recuperar a área degradada. Revista de Direito Ambiental. São Paulo, v. 79, a. 20, jul./set., 2015. p. 157-187.

FONTES, Letícia; GOMES, Lucas Henrique. Samarco só pagou $23 \%$ das multas ambientais por tragédia. O Tempo, Belo Horizonte, 11 dez. 2019. Disponível em: https://www.otempo.com.br/cidades/samarco-so-pagou-23-das-multas-ambientais-portragedia-1.2272408. Acesso em: 12 jan. 2020. 
FRANCO, Carlos Sergio Souza Pinto de Almeida. Segurança de Barragens: Aspectos Regulatórios. 2008. 134 f. Dissertação (Mestrado em Engenharia do Meio Ambiente) Universidade Federal de Goiás, Anápolis, 2008. Disponível em:

https://repositorio.bc.ufg.br/tede/handle/tde/1318. Acesso em: 02 jan. 2019.

GERAQUE, Eduardo. Samarco utilizou modelo mais barato e inseguro de barragem. Folha de São Paulo, São Paulo, 08 dez. 2015. Disponível em: https://www1.folha.uol.com.br/cotidiano/2015/12/1716184-samarco-utilizou-modelo-maisbarato-e-inseguro-de-barragem.shtml. Acesso em: 02 jan. 2020.

GLOBO. Como a mineração ajuda a alavancar a economia brasileira. Globo G1, Brasil, 10 dez. 2018. Disponível em: https://g1.globo.com/especial-publicitario/emmovimento/noticia/2018/12/10/como-a-mineracao-ajuda-a-alavancar-a-economiabrasileira.ghtml. Acesso em: 05 jan. 2020.

HOJE EM DIA. Semad multa Vale em R\$ 330 mil por emitir falso laudo ambiental em relação à barragem de Brumadinho. Hoje em dia, Belo Horizonte, 28 mai. 2019. Disponível em: https://www.hojeemdia.com.br/horizontes/semad-multa-vale-em-r-330-milpor-emitir-falso-laudo-ambiental-em-rela\%C3\%A7\%C3\%A3o-\%C3\%A0-barragem-debrumadinho-1.717154. Acesso em: 12 jan. 2020.

JAIN, Ravinder Kumar. Enviromental impact analysis. New York: Van Nostrand Reinhold, 1977.

MACHADO, Paulo Affonso Leme. Direito Ambiental Brasileiro. 16. ed., rev., atual., e ampl. São Paulo: Malheiros Editores, 2008.

MAINARDE, Thaís Antunes; BERWIG, Juliane Altmann. O desastre de Mariana: A gestão jurídica dos riscos. Revista de Direito Ambiental. São Paulo, v. 90, a. 23, abr./jun., 2018. p. 171-199.

MILARÉ, Édis. Direito do Ambiente. 11. ed., rev., atual. e ampl. São Paulo: Revista dos Tribunais, 2018.

MINAS JR. Beneficiamento: o que você precisa saber. Minas Jr. Consultoria Mineral, Belo Horizonte, 20 set. 2018. Disponível em: https://www.minasjr.com.br/beneficiamento-o-quevoce-precisa-saber/. Acesso em: 02 jan. 2020.

MPMG. Brumadinho: Atuação do MPMG nos 6 meses do rompimento das Barragens. Disponível em:

https://www.mpmg.mp.br/lumis/portal/file/fileDownload.jsp?fileId=8A91CFA96C093F4F01 6C0B69FA56652D. Acesso em: 07 jan. 2020.

NEVES, Luiz Paniago. Segurança de Barragens: Legislação federal brasileira em segurança de barragens comentada. Brasília: Agência Nacional de Mineração, 2018. Disponível em: http://www.anm.gov.br/assuntos/barragens/e-book-livre-legislacao-federalbrasileira-em-seguranca-de-barragens-autor-luiz-paniago-neves. Acesso em: 04 jan. 2020. 
OLIVEIRA, Antonio Inagê de Assis. Introdução à Legislação Ambiental Brasileira e Licenciamento Ambiental. Rio de Janeiro: Lumen Juris, 2005.

PORTARIA. Agência Nacional de Mineração. Portaria nº 70.389, de 17 de maio de 2017. Portarias do Diretor do DNPM. Brasília, DF. 2017. Disponível em: http://www.anm.gov.br/acesso-a-informacao/legislacao/portarias-do-diretor-geral-dodnpm/portarias-do-diretor-geral/portaria-70-389-de-2017/view. Acesso em: 03 jan. 2020.

RESOLUÇÃO. Conselho Nacional do Meio Ambiente. Resolução nº 01, de 23 de janeiro de 1986. Dispõe sobre critérios básicos e diretrizes gerais para a avaliação de impacto ambiental. Livro de Resoluções do CONAMA. Brasília, DF. 1986. Disponível em: http://www2.mma.gov.br/port/conama/processos/61AA3835/LivroConama.pdf. Acesso em: 01 jan. 2020.

RESOLUÇÃO. Conselho Nacional do Meio Ambiente. Resolução no 237, de 19 de dezembro de 1997. Dispõe sobre a revisão e complementação dos procedimentos e critérios utilizados para o licenciamento ambiental. Livro das Resoluções do CONAMA. Brasília, DF. 1997. Disponível em: http://www2.mma.gov.br/port/conama/processos/61AA3835/LivroConama.pdf. Acesso em: 02 jan. 2020.

RESOLUÇÃO. Agência Nacional de Mineração. Resolução nº 13, de 08 de agosto de 2019. Estabelece medidas regulatórias objetivando assegurar a estabilidade de barragens de mineração, notadamente aquelas construídas ou alteadas pelo método denominado "a montante" ou por método declarado como desconhecido e dá outras providências. Coleções de Resoluções ANM: Brasília, DF. 2019. Disponível em:

http://www.anm.gov.br/assuntos/barragens/resolucao-anm-no-13-de-8-de-agosto-de2019.pdf/view. Acesso em: 02 jan. 2020.

RODRIGUES, Sabrina. Retrospectiva: Rompimento da barragem de Brumadinho foi a primeira grande tragédia ambiental do ano. Disponível em:

https://www.oeco.org.br/noticias/rompimento-da-barragem-de-brumadinho-e-a-primeiragrande-tragedia-ambiental-do-ano/. Acesso em: 07 jan. 2020.

SEMAD. Nota a imprensa Licença Samarco. Semad, Belo Horizonte, 25 out. 2019.

Disponível em: http://www.meioambiente.mg.gov.br/noticias/3982-nota-a-imprensa-licencasamarco-. Acesso em: 12 jan. 2020.

TAVEIRA, Ana Lúcia Silva. Análise qualitativa da distribuição de custos ambientais: estudo de caso da Samarco Mineração S.A. 1997. 146 f. Dissertação (Mestrado em Geociências) - Universidade Estadual de Campinas, Campinas, 1997. Disponível em: http://repositorio.unicamp.br/jspui/handle/REPOSIP/287113. Acesso em: 06 jan. 2020.

THOMÉ, Romeu; LAGO, Talita Martins Oliveira. Barragens de rejeitos da mineração: O princípio da prevenção e a implementação de novas alternativas. Revista de Direito Ambiental. São Paulo, v. 85, a. 22, jan./mar., 2017. p. 17-39. 